\title{
Modification of tribological tester t-01m allowing testing in conditions of lubrication
}

\author{
Piotr Sadowski ${ }^{1, *}$, and Emil Czajka ${ }^{1}$ \\ ${ }^{1}$ Kazimierz Pulaski University of Technology and Humanities In Radom, Faculty of Mechanical Engineering, ul. Stasieckiego 54, \\ 26-600 Radom, Poland
}

\begin{abstract}
Researchers often want to develop their experiments in terms of wide range of testing conditions and results possible to acquire. One way to achieve this is to adapt existing testing equipment to new requirements. This paper proposes a method for extending the capabilities of the T-01M tester with a pressure lubrication system of a pin on disc contact, its construction and adjustments. Tribological tests carried out with the presence of a lubricant showed the correct functioning of the modified tester. We obtained several variables for the selected friction pair and friction parameters in the lubricated joint: friction force, friction coefficient, mass wear, friction work, wear intensity and specific wear. Verification tests confirmed suitability of the tester modification, adapting it to friction and wear tests in a lubricated contact. The expanded stand can be used (in the future) for tribological tests of lubricated frictional pairs to measure friction, wear, friction pairs temperature and to compare used lubricants.
\end{abstract}

\section{Introduction}

In the research, many different tribological testers are used. They vary in ways of setting parameters, measuring and recording results. The researchers often want to make a slight change to the testing conditions or measure other variables. They are then forced to buy a new laboratory equipment. This is expensive and timeconsuming (because of delivery time and the time to learn how to use the new device). Moreover, its capabilities often only slightly exceed the equipment used so far. A solution to this type of problem may be outsourcing to other research centres, which is not always beneficial (time, availability, limited control, etc.). Another method of expanding research capabilities is to modify already existing research devices. Examples of this approach can be found in works $[1 \div 4]$. In addition to the work involved in developing the capabilities of testers, there is quite a wide application for such devices. Examples of research carried out on modified positions can be found in numerous publications $[5 \div 9]$.

The $\mathrm{T}-01 \mathrm{M}$ tester is designed to assess the tribological properties of the friction pairs machines and devices. It allows determining the wear resistance and friction coefficient of one material when sliding on another material, considering factors such as slip speed, surface pressure, friction pair materials and other. In order to enable testing for lubricated contacts, we designed and made a modification of the tester. Then, tests were carried out to check the functioning of the modernised test stand. These were the requirements for the lubrication system:

- easy assembly and disassembly of system components and the possibility of easy disassembly of counter samples;
- maintenance-free operation during a multi-hour test; - circulating lubrication with liquid lubricants while ensuring cooling of the friction junction;

- adjustability of the amount of lubricant supplied;

- continuous supply of lubricant by a pump;

- tightness of all elements of the lubrication system;

- disposing of the lubricant excess from the friction junction;

- possibility of lubricant injection point adjustment.

\section{Research stand}

The T-01M pin-disc type tester manufactured by ITeE in Radom is used for testing the tribological properties of materials used for the components of machines and devices forming the friction node[5].

On the basis of tests carried out on the T-01M tester, it is possible to determine the wear resistance and the coefficient of friction of the material, which during the test, slides on another material. The test can be carried out in accordance with DIN 50324 and ASTM G99 with regard to slip speed, surface pressure, presence and type of lubricant and other factors.

Using the $\mathrm{T}-01 \mathrm{M}$ tester equipped with a microprocessor control system and measurements can be made:

- determination of frictional and wear characteristics of various combinations of materials and coatings;

- measuring the ambient temperature of the test contact;

- determination of sliding properties of self-lubricating bearing materials and low-friction coatings;

- determination of the effect of surface hardness and heat treatment of the material to be tested on wear;

- assessment of friction and anti-wear properties of cooling liquids. 


\section{$3 \mathrm{~T}-01 \mathrm{M}$ tester with a designed and made lubrication system}

Construction of the tester allows its modification in a way that ensures lubrication of the friction pair. An example of such a modification is shown in Fig. 1. The lubrication system shown in Fig. 2 is a pressure one, individual with the external circuit of lubricant in the form of a liquid. There is mixed friction in the friction junction, because the surfaces rubbing together are flat and there is no hydrodynamic buoyancy. Regulation of the lubrication intensity is carried out using valves 8 and 20 . The valve 8 serves to regulate the return circuit, i.e. increasing the oil flow through the valve 8 , will reduce the flow through the valve 20 . The valve 20 is used to regulate the oil flow, with which it is possible to achieve drip lubrication, as well as to completely shut off the oil supply. The oil from the friction pair of contact by centrifugal force is discharged on the shield fixing counter sample unit 4 to the oil pan 1 and the hose 11 goes to the container 5 with the pump 7 .

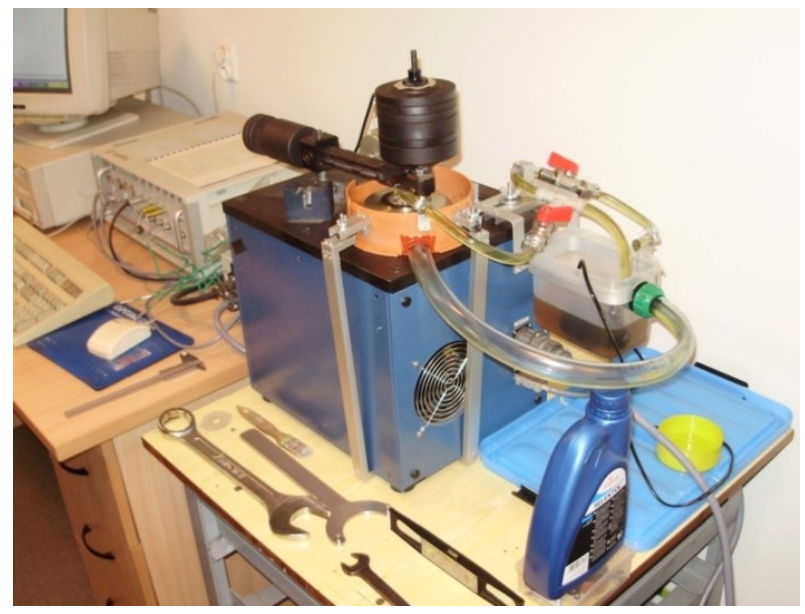

Fig. 1. Tester T-01M modified by the lubrication system of contact friction pair [11].

The current form of the lubrication system has been attained with experimental methods with existing components of the T-01M tester, such as a disc retaining nut. Tests with these elements were unsuccessful, because oil leakage occurred on the thread of the thrust washers. Due to this, the counter sample set 4 (Fig. 2) was made. Its shape ensures proper drainage of oil to the oil pan without leaks outside, and facilitates the installation of counter samples and bowls oil.

\section{Regulation of the amount of lubricant}

The lubrication system is designed to provide the friction junction with a sufficient lubricant to fill the lubrication gap or to create a lubricating film. This system is adapted to hydrodynamic lubrication with liquid lubricants. The fluid additionally cools the friction junction as a result of continuous circulation in the system. The fluid demand depends on its viscosity, the relative speed of rubbing elements and the size of the friction contact. The fluid with lower viscosity will be drained faster from the friction junction than the fluid with higher viscosity. The amount of lubricant supplied
(Figure 3 ) is determined experimentally by observing the lubricated friction joint. It is possible to change the place of supply of the fluid by changing the position of a hose 21 (Fig. 2).

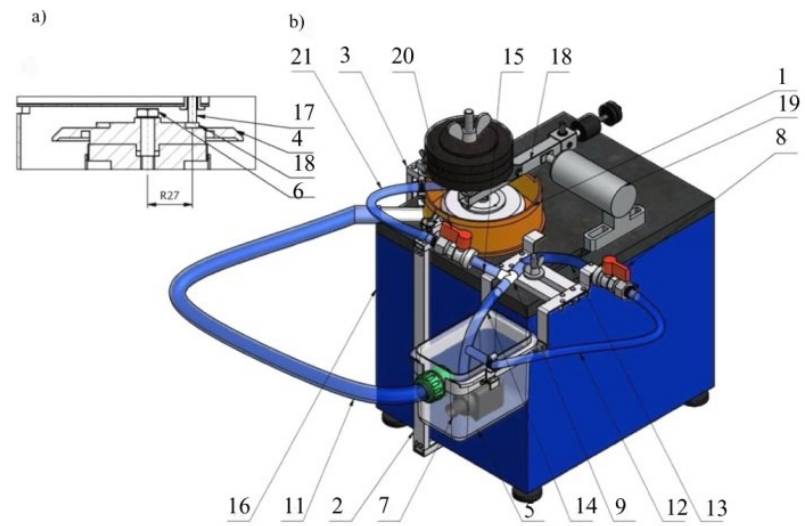

Fig. 2. Tester T-01M modified by the lubrication system: a) the contact of the rubbing pair: 4 - shield team fixing the counter sample, 6 - screw, 17 - sample, 18 - counter sample, b) the most important elements of the lubrication system: 1 - oil pan assembly, 2 - the first holder fixing the oil pan, 3 - the second handle fixing the oil pan, 5 - pump tank assembly, 7 - pump, 8 - valve 1,11 - oil drain hose from the oil pan to the pump tank, 12 - first hose recirculation, 13 - second hose recirculation, 14 - pump hose supplying oil for branching, 15 - a first oil supply hose to contact friction pair, 16 - Tester T-01M, 19 - strain gauge, 20 - valve 2, 21 - a second oil supply hose to contact friction pair [11].

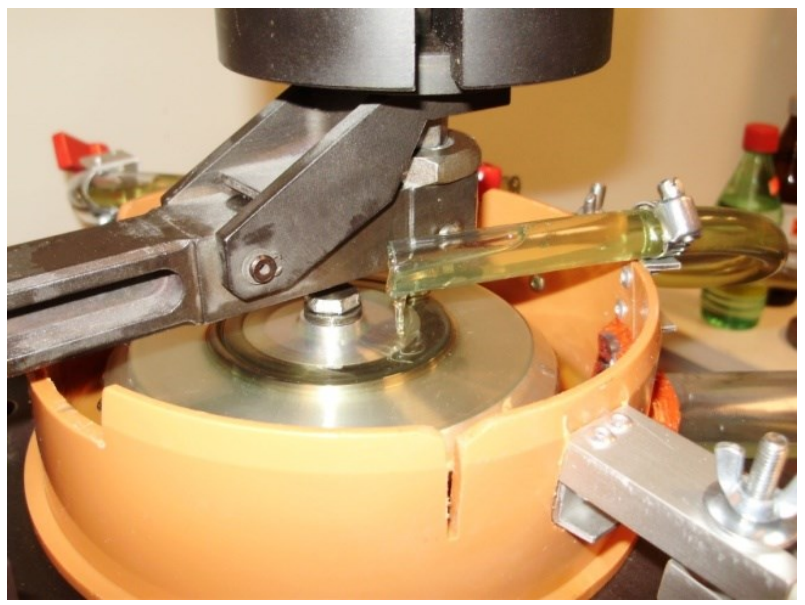

Fig. 3. Lubricated friction node [11].

Fig. 4 shows a hydraulic diagram of the lubrication system made. Regulation of the lubrication intensity is made by appropriate selection of valve settings $z 1$ and $z 2$. This type of lubrication is fully automated. Human is in a supervisory capacity in this process. In the system, there is a constant relative velocity friction element, therefore, by setting the intensity of the lubrication, it is performed only at the beginning of the movement. 


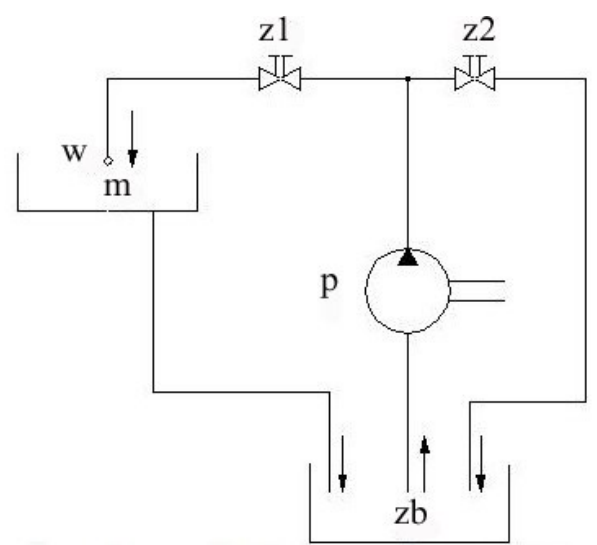

Fig. 4. The scheme of lubrication system for tester T-01M: $\mathrm{zb}$ - lubricant reservoir, $\mathrm{p}$ - pump, $\mathrm{m}$ - oil sump, $\mathrm{z} 1$, $\mathrm{z} 2$ - valves regulating the flow of lubricant, $\mathrm{w}$ - lubricated friction node [11].

\section{Friction vibrations}

Frictional vibrations can sometimes disrupt the operation of the devices, e.g. they can degrade the surface quality of the workpiece on the machine tool. In the case of the $\mathrm{T}-01 \mathrm{M}$ tester, the element susceptible to vibrations is a pin fastened to a lever, which is low friction bearing in a yoke. The condition for measuring the friction force is the pressure of the lever 18 on the strain gauge 19 (Fig. 5), therefore the lever cannot be fixed. Fig. 5 shows directions of friction vibrations generated as a result of counter-clockwise rotation of the disk 17 pushing the lever 18 to the strain gauge 19, which measures frictional force F. Frictional vibrations interfere with the work of the tester, causing horizontal swing movements of the levers that repel and alternately push the lever to the sensor. Increasing the rotational speed of the disc reduces the lever spikes.

An important factor is the roughness of the friction surfaces and their parallelism. As a result of incorrect levelling of the lever in relation to the disc, there were vibrations which caused that the lever dropped from the dial.

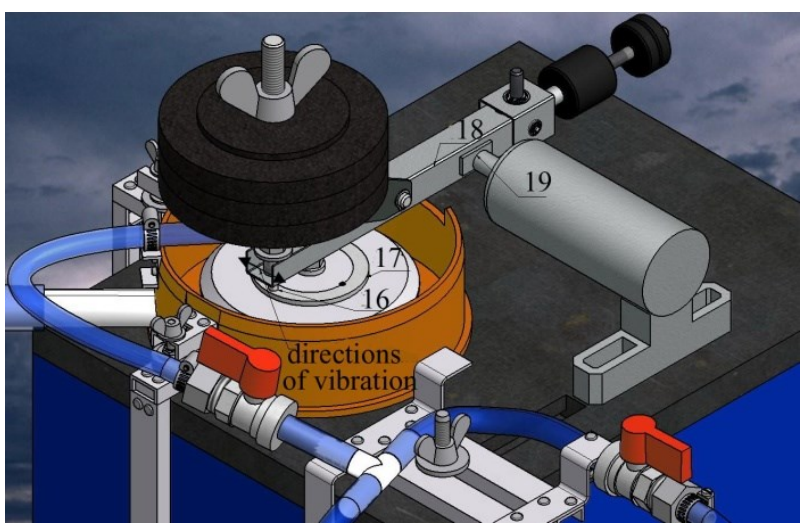

Fig. 5. Place and direction of friction vibrations in the T-01M tester: 16 - pin, 17 - disc, 18 - lever, 19 - strain gauge [11].

The most susceptible element of the friction junction influences the occurrence of relaxation vibrations. The vibration characteristics of various friction nodes are determined experimentally because no unambiguous theories of this process have been developed so far.

\section{Tribological test on the $\mathrm{t}-01 \mathrm{~m}$ tester checking the lubrication system}

A tribological test was performed on the lubricated friction contact using a designed and made lubrication system. The test lasted 5 hours and was divided into two stages. The first stage lasted one hour, after which the condition of the lubrication system was checked for oil leaks. A small leak was observed around the oil drain hose 11 on the oil pan assembly 1 (Fig. 2), and then the second stage of the test, which lasted 4 hours, was initiated. Table 1 presents the adopted fixed values of the test parameters.

Table 1. General conditions of the tribological test carried out [11].

\begin{tabular}{|l|l|}
\hline Spindle speed $[\mathrm{m} / \mathrm{s}]$ & 0.4 \\
\hline Load $[\mathrm{N}]$ & 39.24 \\
\hline Unit pressure $[\mathrm{MPa}]$ & 2 \\
\hline The road of friction $[\mathrm{m}]$ & 8640 \\
\hline Ambient temperature $\left[{ }^{\circ} \mathrm{C}\right]$ & 21 \\
\hline Air humidity $[\%]$ & 34 \\
\hline Lubricant & $\begin{array}{l}\text { Oil Special type Selektol } \\
\text { SAE 20W/40. API SD }\end{array}$ \\
\hline
\end{tabular}

The lubricant used in the tribological test was a multi-grade special Selektol SAE 20W / 40 engine oil, API SD (oil for carburettors operating in severe conditions with enhanced anti-corrosion, antioxidant and anti-wear properties [7]), which has the following properties [8]:

- the maximum kinematic viscosity at $-17.8^{\circ} \mathrm{C}$ is 10,500 $\mathrm{mm} 2 / \mathrm{s}$;

- the minimum kinematic viscosity at $98.9{ }^{\circ} \mathrm{C}$ is 12.9

$\mathrm{mm} 2 / \mathrm{s}$;

- the minimum viscosity index is WLmin $=113$;

- designed to work in difficult conditions;

- increased anti-corrosion, anti-oxidation and anti-wear properties.

\section{Information about the sample and counter sample}

Counter sample made of alloy tool steel for cold work NC6, the hardness after quenching is $62 \mathrm{HRC}$. The friction radius, i.e. the shift of the sample axis relative to the counter sample, was $\mathrm{R}=27 \mathrm{~mm}$ (fig. 6).
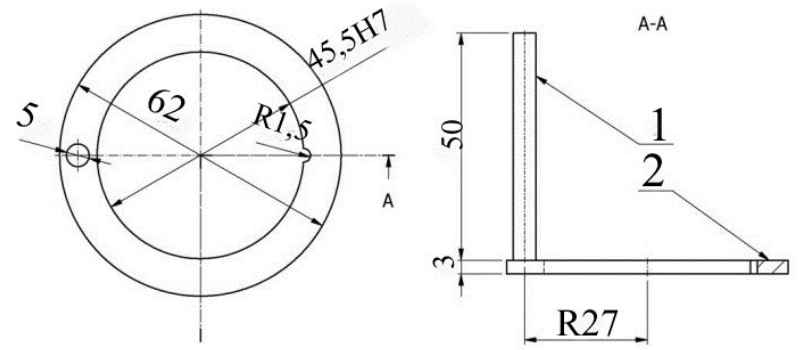

Fig. 6. The dimensions of the sample and counter sample: 1 - sample 2 - counter sample [11]

The sample was made of Armco iron and subjected to normalising annealing at $950{ }^{\circ} \mathrm{C}$ for 30 minutes. The microhardness measurement showed uniformity of 
hardness over the entire surface, because measurements at the grain boundary were similar to measurements inside grains. Fig. 7 shows the microstructure of the Armco iron sample with a hardness of $99.6 \mathrm{HV}$.

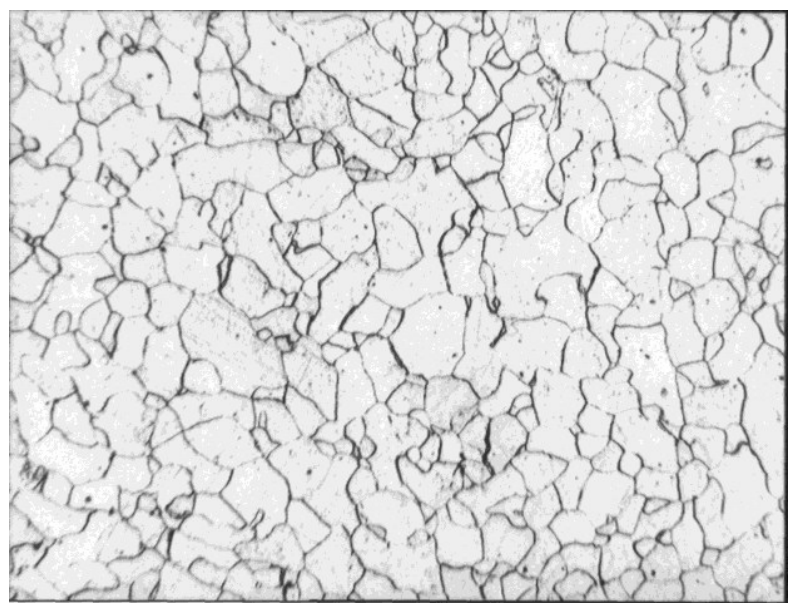

Fig. 7. Armco iron microstructure (100x magnification) [11].

\section{Measurement of friction force and coefficient of friction}

Fig. 8 presents graphs of friction force $\mathrm{F}$ as a function of time divided into each hour of the test separately. Measurement is not continuous, takes place at 2 -second intervals, i.e. each graph consists of approximately 1800 points connected by straight lines. The graph shows the occurrence of friction vibrations between the rotating disc and the mandrel. In this system, the mandrel is susceptible to vibrations. The frictional vibrations change the pressure of the lever on the strain gauge (Fig. 5 ), the value of which varies between $0 \div 5.42 \mathrm{~N}$.

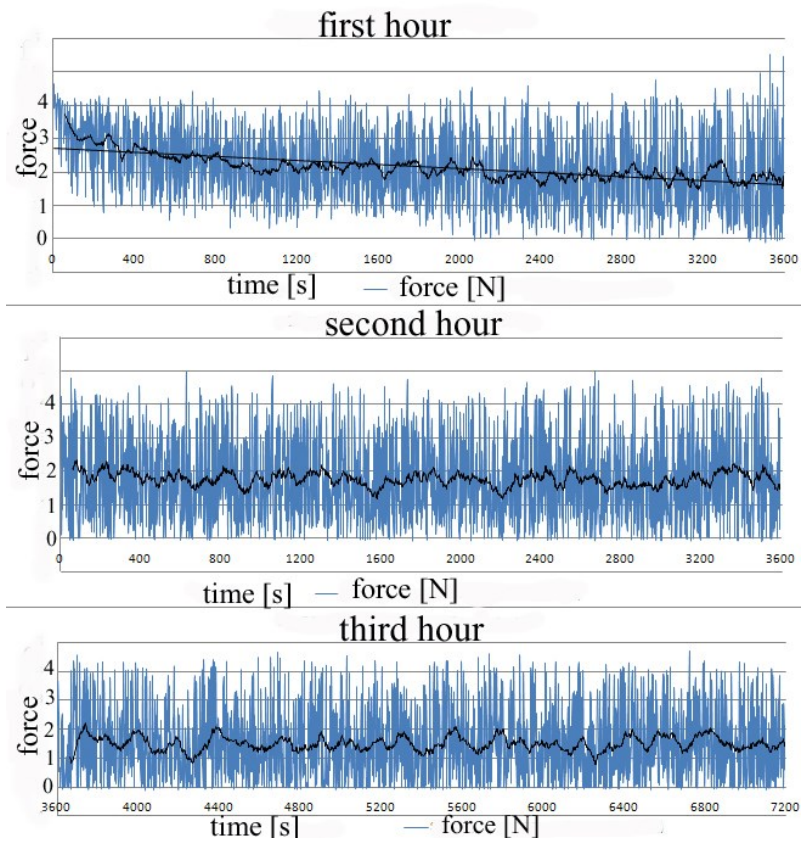

Fig. 8. Graph of friction forces [N]as a function of time [11].
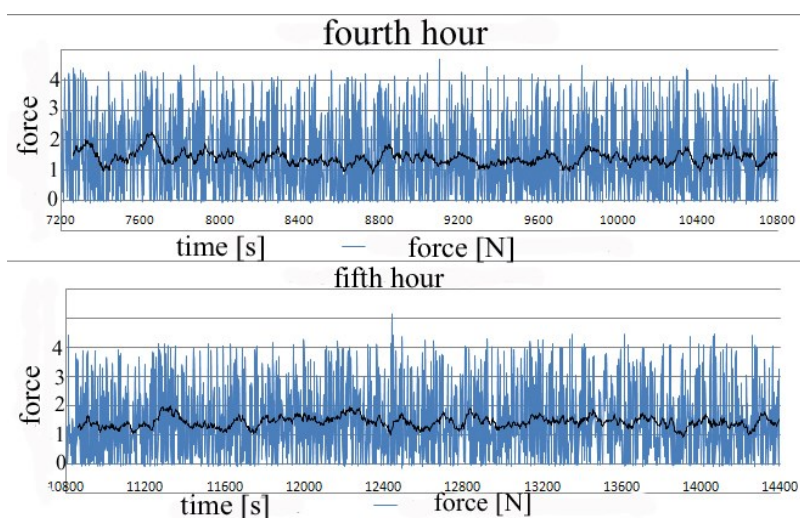

Fig. 8. (continued) Graph of friction forces $[\mathrm{N}]$ as a function of time [11].

On the basis of the graph in Fig. 9, it was assumed that the break-in period ends after 12,000 seconds, i.e. 3 hours and 20 minutes, of the test lasting 5 hours.

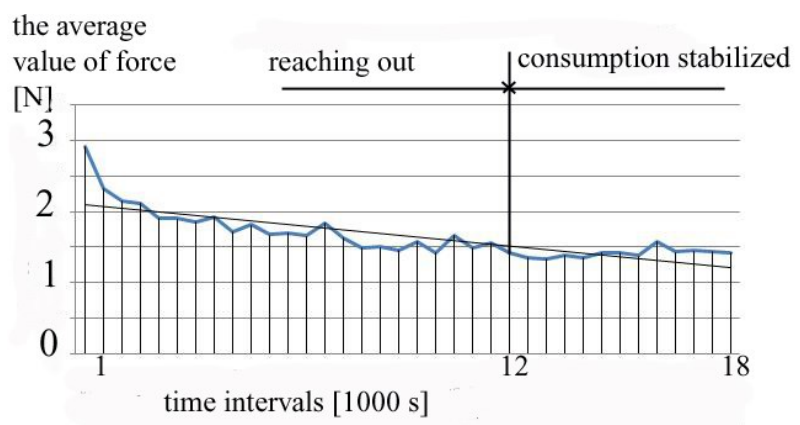

Fig. 9. A graph showing the dependence of the mean value of force $\mathrm{F}$ on the time intervals in which it was calculated [11].

$F_{t}$ friction force was taken as the average value of this force during the whole test (Fig. 8), which was 1.66 $\mathrm{N}$. The average value of the friction force during the whole test varied from $1.33 \div 2.91 \mathrm{~N}$.

The coefficient of friction, in the whole period of time is:

$$
\mu=\frac{F_{t}}{F_{n}}=\frac{1,66}{39,24}=0,042
$$

where: $F_{t}$ - friction force $[N], F_{n}$ - pressure force on the ground $[\mathrm{N}]$.

On the above graphs (Fig. 8 and Fig. 9), there are different time intervals. This difference stems from the fact of division of the test into two stages. In the first stage, which lasted $3600 \mathrm{~s}$, the machine was stopped, while in the second test stage, the time was counted from zero, which can be seen in Fig. 8. In Fig. 9 the time in the second stage is calculated from $3600 \mathrm{~s}$ in order to facilitate the execution of the graph of the average value of the friction force.

\section{The friction force at the time of wear stabilised}

Fig. 10 shows the course of wear of elements for sliding friction as a function of time, called the Lorenz curve. 
The force diagram $\mathrm{F}$ as a function of time for the stabilised wear period consists of 1780 points connected by straight lines, that is why it is illegible. In order to

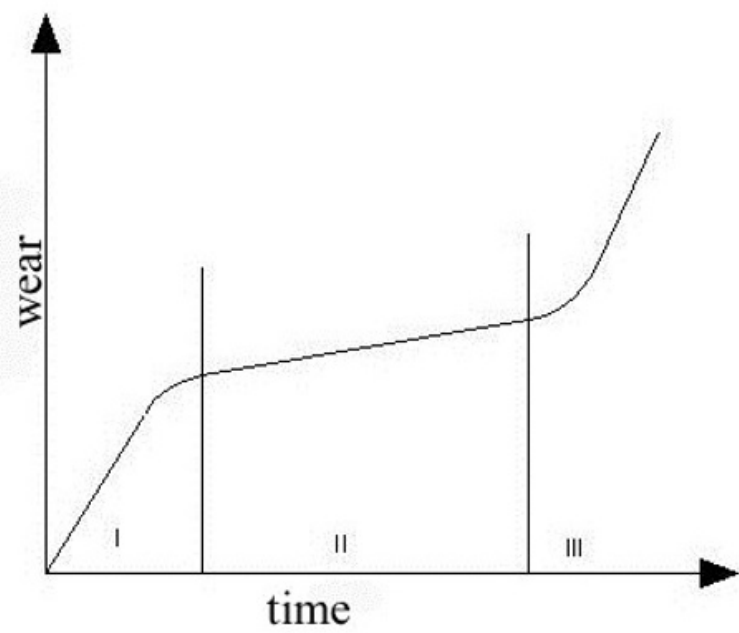

Fig. 10. Lorenz curve for the course of sliding friction wear: I - break-in period, II - period of stable wear during normal operation, III - period of emergency wear [11].

improve the readability of the graph, the mean values of friction force were calculated in 24 time intervals (Figure 11). It has been assumed that the stabilised wear starts after 3 hours and 20 minutes of the test duration and lasts until the end of the test, i.e. for 6000 seconds.

During the stabilised wear, the average value of friction force F (Fig. 11) was $1.42 \mathrm{~N}$. The value of this force varied in the range of $1.27 \div 1.61 \mathrm{~N}$. For this interval, the friction coefficient $\mu$, which is equal to:

$$
\mu=\frac{F_{t}}{F_{n}}=\frac{1,42}{39,24}=0,036
$$

where: $F_{t}$ - friction force [N], $F_{n}$ - pressure force on the ground $[\mathrm{N}]$.

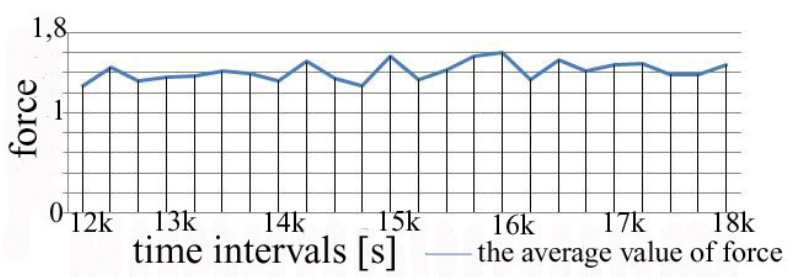

Fig. 11. Graph of the average force value $F[N]$ in the time intervals for stabilised wear [11].

\section{Measure of wear}

The wear measure can be determined by an absolute or relative method. Determination of the wear measure $Z$. The absolute method is carried out by measuring the mass loss $m_{z}$, the volume or height of the material loss $\mathrm{h}_{\mathrm{z}}$. This method requires the process conditions, particularly the road or the time of its course.

The relative method of wear measurement is a reference to specific parameters. The most common method is the wear intensity I (wear rate), i.e. the reference mass, volume or linear loss to time unit, friction path or friction work, etc. After determining wear $\mathrm{Z}$ or intensity of wear I can determine the resistance to wear, which is the inverse $\mathrm{Z}$ or $\mathrm{I}$. respectively.

For measurement of wear in the tribological test in the mandrel-disc contact, the measure of wear was the weight loss (table 2). The loss of volume and height for wear adopted test conditions was immeasurable. The loss of the counter sample mass is less than the loss of the sample. Therefore, it can be concluded that the countersample has a greater wear resistance than the sample. The loss of the counter sample mass is on the verge of measurement error, i.e. the test time of the lubricated contact should be much longer. The task of the test was to check the operation of the lubrication system at the assumed parameters.

Table 2. The results of measurements of sample weight and counter sample weight [11].

\begin{tabular}{|c|c|c|}
\hline & $\begin{array}{c}\text { Sample } \\
\text { (pin) }\end{array}$ & $\begin{array}{c}\text { Counter-sample } \\
\text { (disc) }\end{array}$ \\
\hline Weight before the test $[\mathrm{g}]$ & 7.77060 & 32.07178 \\
\hline Weight after the test $[\mathrm{g}]$ & 7.77002 & 32.07172 \\
\hline Wear weight $[\mathrm{g}]$ & 0.00058 & 0.00006 \\
\hline
\end{tabular}

The mass wear intensity for a sample can be calculated as the mass loss related to time, distance and friction work (table 1) from the following formulas:

- wear intensity measured by weight loss with respect to friction time $\mathrm{I}_{\mathrm{m} 1}$

$$
I_{m 1}=\frac{m_{z}}{\tau_{t}}=\frac{0,00058}{17600}=3,295 \cdot 10^{-8}[\mathrm{~g} / \mathrm{J}]
$$

where: $\mathrm{m}_{\mathrm{z}}$ - mass of wear $[\mathrm{g}], \tau_{\mathrm{t}}$ - time of friction $[\mathrm{s}]$; - wear intensity measured by the weight loss in relation to the road friction $\mathrm{I}_{\mathrm{m} 2}$

$$
I_{m 2}=\frac{m_{z}}{l_{t}}=\frac{0,00058}{8640}=6,713 \cdot 10^{-8}[\mathrm{~g} / \mathrm{J}]
$$

where: $l_{t}$ - Road of friction $[\mathrm{m}]$;

- friction work $L_{t}$

$$
\mathrm{L}_{\mathrm{t}}=\mathrm{F}_{\mathrm{t}} \cdot \mathrm{l}_{\mathrm{t}}=1,66 \cdot 8640=14342,4[\mathrm{~J}] 2,4[\mathrm{~J}]
$$

where: $F_{t}$ - the average value of the friction force $[N], l_{t}$ sliding distance $[\mathrm{m}]$;

- wear intensity measured by weight loss in relation to friction work $\mathrm{I}_{\mathrm{m} 3}$

$$
I_{m 3}=\frac{m_{z}}{L_{t}}=\frac{0,00058}{14342,4}=4,044 \cdot 10^{-8}[\mathrm{~g} / \mathrm{J}]
$$

$\mathrm{L}_{\mathrm{z}}$ wear specific work samples is determined depending on the friction work of weight loss:

$$
L_{z}=\frac{L_{t}}{m_{z}}=\frac{14342,4}{0,00058}=24,728 \cdot 10^{6}[\mathrm{~J} / \mathrm{g}]
$$




\section{Summary}

The most important factor in improving reliability, efficiency and durability of tribomechanical systems is their lubrication. The choice of lubricant and the method of its delivery determine the extent to which the abovementioned parameters will be improved. Lubrication also reduces energy required to overcome friction, i.e. reduces the operating costs of the machines.

The biggest influence on the choice of lubricants, primarily oils, are operating conditions, such as temperature and load. Temperature is directly proportional to the viscosity and the pressure (load) inversely proportional. Variable working conditions of tribomechanical systems affect the viscosity of most lubricants, which is not beneficial. Therefore, before selecting a lubricant, the conditions under it will work should be determined.

The choice of the lubricant supply method is influenced, among other things, by the design of tribomechanical elements and machines, as well as costs. Hydrostatic lubrication uses expensive components. It is used when there is no spontaneous hydrodynamic buoyancy. Therefore, if possible, hydrostatic lubrication is replaced by hydrodynamic lubrication thanks to the change of the friction node structure that ensures spontaneous hydrodynamic buoyancy.

The examination of tribological processes with the presence of a lubricant is possible on research machines. The T-01M tester modified with a lubrication system can also test these processes with the presence of lubricant in the liquid form.

Modification of the $\mathrm{T}-01 \mathrm{M}$ tribological tester was made according to assumptions. Most of the assumptions were met without any problems, the most difficult problem to solve was the tightness of lubrication system components. The problem of tightness around the friction node was solved by using a disc fixing the counter sample and draining oil into the oil sump. Contacting surfaces of the counter-sample and the disc are flat, therefore the oil getting in between these surfaces makes it difficult to dismantle the countersample. This issue is less burdensome due to the possibility of removing or fixing the counter. In addition, there was a problem with the oil sump lacking tightness, that was solved by using an oil-resistant silicone sealant.

The tribological test, which lasted five hours, proved to be so short that the weight loss of the counter-sample was on the verge of measurement error, and the loss of volume and height of the sample material were unmeasurable. The purpose of the test was only to check the correct operation of the lubrication system during the tribological tests of the lubricated joint. The test aimed at determination of the wear rate of tribomechanical elements should take much longer or parameters such as speed or load should be increased. Before starting the test, the sample should be precisely levelled to prevent it from sliding of the counter-sample as a result of vibrations caused by the unevenness of the rubbing surfaces.

The lubrication system does not have an oil filter, but it is possible to install such a system, e.g. on a hose discharging the oil from the oil pan into the pump tank. The lack of the oil filter may cause faster wear of the friction junction components.

The work is of a constructional nature and is directed at testing the operational properties of lubricants in a flat friction contact of solids, mainly metals. At this stage, the work is of practical importance. In the future the results obtained using the modified tester can be used for the thermodynamic interpretation of friction and lubrication.

An element of novelty in relation to the existing solutions in the work carried out, is the friction contact lubrication system. It is possible to further modified by adjusting the temperature of the lubricant.

\section{References}

1. J. Ciecieląg, Tribologia 3, 35-43 (2004)

2. W. Piekoszewski, M. Szczerek, W. Tuszynski, Wear 249, 188-193 (2001)

3. M. Michalak, R. Michalczewski, J. Wulczyński, Tribologia 6, 79-95 (2014)

4. R. Michalczewski, M. Szczerek, W. Tuszyński, J. Wulczyński, Tribologia 1, 113-127 (2009)

5. Weimin Liu, J. L. Duda, E. E. Klaus, Wear 199 , 217-221 (1996)

6. Y. N. Liang, S. Z. Li, D. F. Li, S. Li, Wear 199 6673 (1996)

7. B.K. Gandhi, S.N. Singh, V. Seshadri, Tribology International 32, 275-282 (1999)

8. A. Ramírez, J. Gallego, J. R. Marcobal, C Blázquez, Wear 322-323, 164-170 (2015)

9. C. P. Koshy, P. K. Rajendrakumar, M. V. Thottackkad, Wear 330-331, 288-308 (2015)

10. Instrukcja obsługi: T-01M Tester typu trzpień tarcza. Radom, Instytut Technologii Eksploatacji Zakład Tribologii, (1997)

11. E. Czajka, Modyfikacja testera tribologicznego T01M umożliwiająca badanie styku smarowanego, Praca magisterska, Politechnika Radomska, Wydział Mechaniczny, Radom (2010)

12. PN-ISO 6743-99:2009: Środki smarne, oleje przemysłowe i produkty podobne (klasa L) Klasyfikacja - część 99: Postanowienia ogólne

13. Katalog produktów naftowych. Wyd. Zjed. Przemysłu Rafineryjnego i Petrochemicznego „Petrochemia”, (1979) 